\title{
Erratum to: Modulation of neutrophil NETosis: interplay between infectious agents and underlying host physiology
}

\author{
Sinuhe Hahn • Stavros Giaglis • Chanchal Sur Chowdhury • \\ Irene Hösli • Paul Hasler
}

Published online: 5 June 2013

(C) Springer-Verlag Berlin Heidelberg 2013

Erratum to: Semin Immunopathol

DOI 10.1007/s00281-013-0380-x

Correction: The family name of Chanchal Sur Chowdhury has been misspelled

The correct author line must read:

Sinuhe Hahn - Stavros Giaglis - Chanchal Sur Chowdhury • Irene Hösli • Paul Hasler

The online version of the original article can be found at http:// dx.doi.org/10.1007/s00281-013-0380-x.

S. Hahn $(\bowtie) \cdot$ S. Giaglis $\cdot$ C. S. Chowdhury

Department of Biomedicine, University Hospital Basel,

Basel, Switzerland

e-mail: SHahn@uhbs.ch

S. Giaglis $\cdot$ P. Hasler

Department of Rheumatology, Kantonsspital Aarau,

Aarau, Switzerland

I. Hösli

Department of Obstetrics, University Hospital Basel,

Basel, Switzerland

S. Hahn

Laboratory for Prenatal Medicine, Department Biomedicine,

University Women's Hospital, University Hospital Basel,

Hebelstrasse 20, Basel CH 4031, Switzerland 